\title{
Male Gonadotroph Adenoma: Report of Three Cases and a Review of the Literature
}

\author{
Hisato Tatsuoka ${ }^{1}$, Shojiro Inano ${ }^{1}$, Yoshiyuki Hamamoto ${ }^{1}$, Yuki Takahashi ${ }^{2}$, Jun Takahashi ${ }^{2}$, \\ Shozo Yamada ${ }^{3}$, Toshiaki Sano ${ }^{4}$ and Hiroyuki Koshiyama ${ }^{1}$
}

\begin{abstract}
We herein report three cases of gonadotroph adenoma in men (36-72 years of age) presenting with visual impairment and suprasellar masses measuring approximately 20 to $30 \mathrm{~mm}$ in diameter. Endocrinological examinations were normal, except for slightly increased follicle stimulating hormone (FSH) levels in two cases. Based on the tentative diagnosis of non-functioning pituitary adenoma, transsphenoidal surgery was performed, which revealed that the tumors consisted of FSH- and LH-positive cells. As gonadotroph adenoma is very common among patients with clinically silent pituitary adenoma, it should be diagnosed using pathological examinations.
\end{abstract}

Key words: pituitary adenoma, gonadotroph, FH, LSH, silent

(Intern Med 52: 1199-1202, 2013)

(DOI: 10.2169/internalmedicine.52.7855)

\section{Introduction}

Sellar lesions include lesions of various etiologies; however, pituitary adenoma is common (1-4). Approximately $80 \%$ of pituitary macroadenomas have been reported to be nonfunctioning pituitary adenomas $(4,5)$. One of the current authors (S. Y.) and others have reported the findings of an immunohistochemical study of a total of 213 clinically nonfunctioning pituitary adenomas, of which $64 \%$ were silent gonadotroph adenomas (5). Male gonadotropin-secreting pituitary adenoma rarely presents with significant symptoms based on hypersecretion of gonadotropins, except in children, who manifest precocious puberty $(6,7)$. Therefore, it is almost impossible to diagnose this condition preoperatively. We herein present three cases of male gonadotroph pituitary adenoma and also provide a review of the pertinent literature.

\section{Case Report}

Between January 2008 and December 2010, we found 18 cases of pituitary adenoma that were treated with surgery. Postoperatively, in all cases, the tissue samples were stained immunohistochemically with adrenocorticotropic hormone (ACTH), thyroid stimulating hormone (TSH), prolactin (PRL), luteinizing hormone (LH), follicle stimulating hormone (FSH) and growth hormone (GH). To detect FSHpositive cells, we used an antibody specific to FSH- $\beta$ that exhibited no cross-reaction to $\alpha$-subunit, LH or TSH. Among the 18 cases, there were three cases of gonadotroph adenoma. The remaining cases included eight cases of growth hormone-producing adenoma, two cases of prolactinoma and five cases of null cell tumors.

The first case involved a 36-year-old man who was referred to our hospital presenting with bitemporal hemianopia. Magnetic resonance imaging (MRI) revealed an intrasuprasellar mass measuring approximately $25 \mathrm{~mm}$ in diameter that was considered to be responsible for the patient's symptoms (Fig. 1). The patient had no history of premature puberty. Endocrinological examinations revealed normal findings for the basal secretion of ACTH, TSH, PRL, LH, FSH and $\mathrm{GH}$ and the responses to loading tests of corticotropinreleasing hormone $(\mathrm{CRH})$, thyrotropin-releasing hormone

\footnotetext{
${ }^{1}$ Center for Diabetes \& Endocrinology, Tazuke Kofukai Foundation Medical Research Institute Kitano Hospital, Japan, ${ }^{2}$ Center for Neurology and Neurosurgery, Tazuke Kofukai Foundation Medical Research Institute Kitano Hospital, Japan, ${ }^{3}$ Department of Neurosurgery, Toranomon Hospital, Japan and ${ }^{4}$ Department of Pathology, Toranomon Hospital, Japan

Received for publication March 29, 2012; Accepted for publication January 31, 2013

Correspondence to Dr. Yoshiyuki Hamamoto, hamamoto@kitano-hp.or.jp
} 


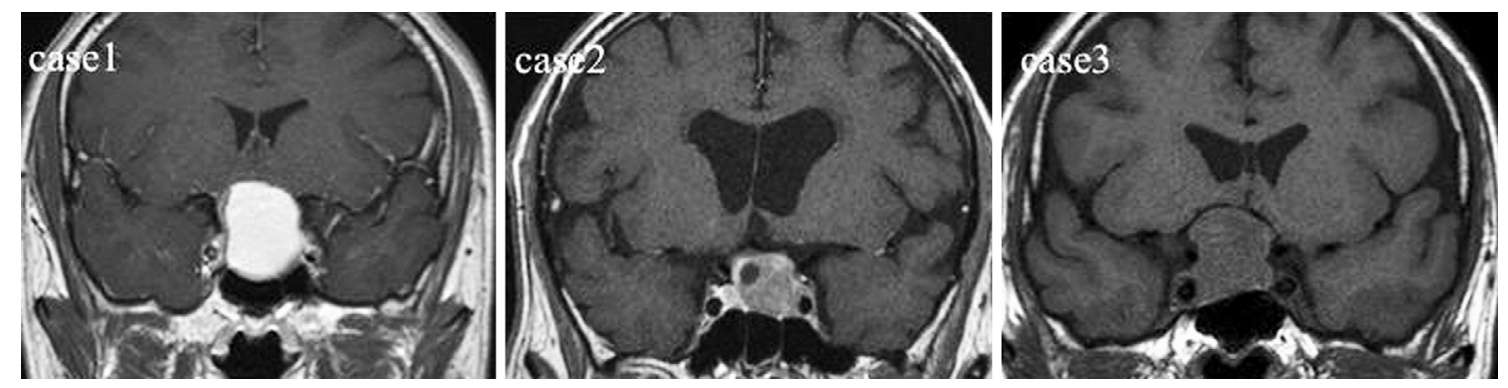

Figure 1. Magnetic resonance imaging of the three cases. Cases 1 and 2 include enhanced images; however, the image of Case 3 was not enhanced due to the presence of bronchial asthma.

Table. Summary of the Cases of Male Gonadotroph Adenoma

\begin{tabular}{lrrrl}
\hline & case1 & case2 & case3 & normal range \\
\hline age/sex & $36 \mathrm{M}$ & $72 \mathrm{M}$ & $51 \mathrm{M}$ & \\
FSH(mIU/mL) & 6.68 & 16.40 & 20.90 & $1.55-9.74$ \\
Max FSH & 12.20 & 30.80 & 32.00 & \\
LH(mIU/mL) & 2.80 & 5.69 & 4.06 & $2-12$ \\
Max LH & 23.60 & 23.80 & 21.20 & \\
$\alpha$-subunit $(\mathrm{ng} / \mathrm{mL})$ & $\mathrm{ND}$ & $\mathrm{ND}$ & 0.6 & \\
Testosterone $(\mathrm{ng} / \mathrm{mL})$ & 2.60 & $\mathrm{ND}$ & 10.0 & $2.07-7.61$ \\
ACTH(pg/mL) & 46.9 & 31.1 & 35.4 & $7.2-63.3$ \\
Max ACTH & 78.0 & 108 & 42.5 & \\
Cortisol $(\mu \mathrm{g} / \mathrm{mL})$ & 14.1 & 15.5 & 7.4 & $4.5-21.1$ \\
Max cortisol & 18.1 & 21.2 & 10.6 & \\
GH(ng/mL) & 0.287 & 0.17 & 0.050 & vary on age \\
Max GH & 2.527 & 7.157 & 1.602 & \\
IGF-1 $(\mathrm{ng} / \mathrm{mL})$ & 192 & 149 & 121 & vary on age \\
TSH $(\mu \mathrm{IU} / \mathrm{mL})$ & 1.38 & 1.49 & 0.52 & $0.35-4.94$ \\
Max TSH & 6.91 & 7.00 & 5.23 & \\
Free T $(\mathrm{ng} / \mathrm{dL})$ & 0.99 & 1.05 & 1.08 & $0.70-1.48$ \\
PRL $(\mathrm{ng} / \mathrm{mL})$ & 20.1 & 8.60 & 19.1 & $3.67-17.9$ \\
\hline
\end{tabular}

(TRH), luteinizing hormone-releasing hormone (LHRH) and growth hormone releasing factor (GRF) (Table). The patient was diagnosed with a nonfunctional pituitary adenoma, which was resected using the transsphenoidal approach. A postoperative immunohistochemical analysis revealed that more than $50 \%$ of the tumor cells were FSH-positive and a small percent were LH-positive (Fig. 2). The other hormones listed above were negative.

The second case involved a 72-year-old man who presented with diplopia and ptosis of the left eyelid. He had a history of diabetes mellitus that was treated with an oral hypoglycemic agent; however, he had no known history suggesting premature puberty. MRI revealed a sellar mass measuring approximately $20 \mathrm{~mm}$ in diameter with suprasellar extension to the left cavernous sinus that was compressing the optic chiasm (Fig. 1). The patient was admitted to our hospital. Endocrinological examinations were performed, which revealed a slightly high level of basal FSH secretion (16.40 $\mathrm{mIU} / \mathrm{mL})$, although other endocrinological markers, including the basal secretion of ACTH, TSH, PRL, LH and $\mathrm{GH}$ and loading tests of CRH, TRH, LHRH and GRF, were normal (Table). The patient underwent transsphenoidal resection of the pituitary tumor. Immunohistochemically, more than $50 \%$ of the tumor cells were FSH-positive, 20\% were LH-positive and few were Ki-67-positive (Fig. 2). Other hormones were negative.

Both patients showed improvements in visual disturbance after surgery. Loading tests performed after surgery demonstrated no findings of adrenal deficiency or hypothyroidism. Since there were no obvious deficiencies in the postoperative growth hormone levels, the levels of growth hormone and IGF-1 were not followed. Patients 2 and 3 have exhibited no findings of recurrence (four years and two years after surgery, respectively); however, the patient of Case 1 dropped out and could not be followed.

\section{Discussion}

Two of the authors (T.S. and S.Y.) have proposed that pituitary adenomas can be classified into the following groups: the GH-PRL-TRH group, the ACTH group and the FSH-LH group $(5,7)$. Pituitary adenomas can also be classified into clinically active and clinically silent adenomas. Clinically "silent" pituitary adenomas include silent somatotroph cell adenomas (8), silent corticotroph cell adenomas (3) and silent gonadotroph adenomas. In particular, silent corticotroph cell adenomas have been reported to exhibit aggressive behavior with progressive visual disturbances and/or infarction $(3,9,10)$.

We herein presented three cases of male gonadotropinsecreting pituitary adenoma, all of which were diagnosed postoperatively. It has been reported that $64 \%$ of clinically nonfunctioning pituitary adenomas are silent gonadotroph adenomas (5). One study indicated that, among 579 patients with nonfunctioning pituitary adenomas over 20 years of age, 304 patients $(52.3 \%)$ had silent gonadotroph adenomas (11). Therefore, it is possible that male gonadotroph pituitary adenomas commonly exist in adult men clinically diagnosed with 'nonfunctioning pituitary adenoma;' however, there have been only a few reports investigating this phenomenon in Japanese subjects. Surgery is considered to be the first choice for patients with inactive endocrine adenomas (12). In approximately $70 \%$ of all cases of clinically nonfunctioning pituitary adenoma, the patient experiences improvements in visual impairment $(13,14)$. In studies of 

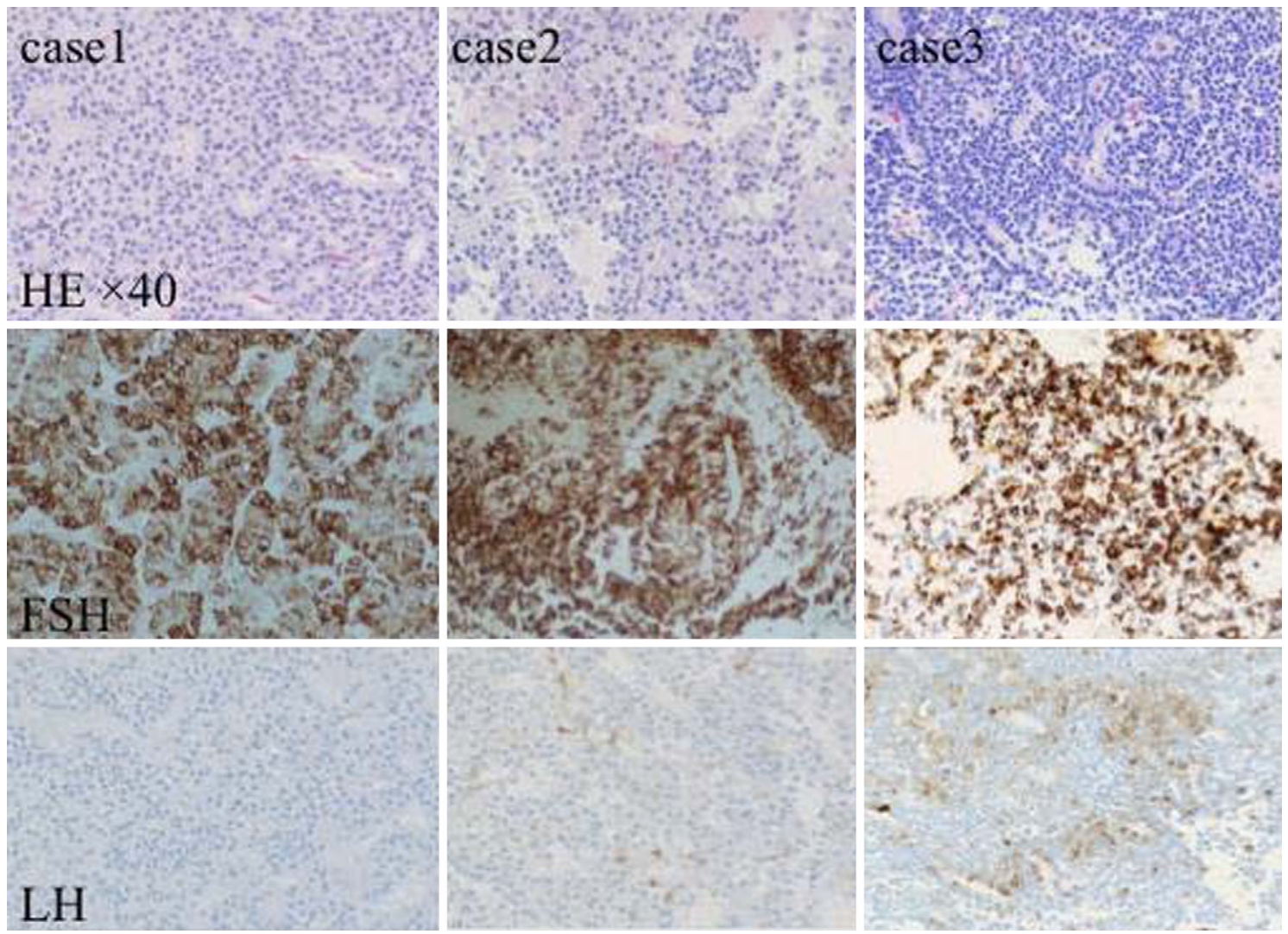

Figure 2. Pathological findings of the three cases. The pathological findings of Hematoxylin and Eosin staining $\times \mathbf{4 0}$ and immunohistochemical labeling of FSH-positive cells and LH-positive cells. In Case 1, more than $50 \%$ of the tumor cells were FSH-positive and a small percent were LH-positive. In Case 2, more than $50 \%$ of the tumor cells were FSH-positive and $20 \%$ were LH-positive. In Case 3, a small percentage of the tumor cells were FSH- and LH-positive.

patients who do not receive postoperative radiotherapy, the regrowth rates range between $6 \%$ and $46 \%$ (15). Noh et al. reported that, in 10 of 289 cases, tumor regrowth was found more than four years after surgery (16). Radiation therapy is used most commonly after transsphenoidal surgery to prevent regrowth of residual gonadotroph adenoma tissue (13). Regrowth is observed in $0-36 \%$ of cases after prophylactic postoperative radiotherapy (17). Recently, several therapeutic options have been developed $(6,12,13,18)$. Both somatostatin analogues and dopamine agonists have been found to be of some efficacy in selected patients with nonfunctioning pituitary adenoma, with the latter drugs being significantly more effective in reducing tumor volumes (18). However, the administration of gonadotropin-releasing hormone agonist analogs in patients with gonadotroph adenomas generally produces no effects on secretion or adenoma size (13).

There are several reasons why few cases of gonadotroph adenoma can be diagnosed preoperatively. First, gonadotroph adenoma is unlikely to develop overt clinical manifestations due to hormone excess in men until the tumor creates a 'mass effect' by pressing on surrounding organs and manifesting with neurological disorders $(12,19,20)$. An excessive amount of gonadotropins may represent oligomenorrhea, amenorrhea or ovarian hyperstimulation in premenopausal women and premature puberty in boys; how- ever, no symptoms are observed in adult men or postmenopausal women $(6,12,19,20)$. Second, gonadotroph adenomas secrete inefficiently and variably, and most patients with gonadotroph adenomas exhibit a normal gonadal function, including normal fertility (7). Third, there are discrepancies between the serum levels of gonadotropins and their subunits in vivo and their secretion in vitro (20). The basal concentrations of gonadotropin and their free subunits are elevated in $30-50 \%$ of cases $(6,19)$. It should be noted that the patient of Case 3 had few gonadotroph cells compared to the serum FSH level.

In conclusion, gonadotropin-producing pituitary adenoma commonly exists in patients with clinically silent pituitary adenoma; thus, gonadotroph adenoma should be diagnosed using pathological examinations in adult men.

The authors state that they have no Conflict of Interest (COI).

\section{References}

1. Koshiyama H, Sakamoto M, Fujiwara K, Kim YC, Teraura T, Koh T. Chondroid chordoma presenting with hypopituitarism. Intern Med 31: 1366-1369, 1992.

2. Koshiyama H, Ohgaki K, Hida S, et al. Metastatic renal cell carcinoma to the pituitary gland presenting with hypopituitarism. J En- 
docrinol Invest 15: 677-681, 1992.

3. Sakaguchi H, Koshiyama H, Sano T, Hashimoto N, Aoki N, Nakao K. A case of nonfunctioning pituitary adenoma resembling so-called silent corticotroph adenoma. Endocr J 44: 329-333, 1997.

4. Sanno N, Oyama K, Tahara S, Teramoto A, Kato Y. A survey of pituitary incidentaloma in Japan. Eur J Endocrinol 149: 123-127, 2003.

5. Yamada S, Ohyama K, Taguchi M, et al. A study of the correlation between morphological findings and biological activities in clinically nonfunctioning pituitary adenomas. Neurosurgery 61: 580-584, 2007.

6. Snyder PJ. Gonadotroph cell adenomas of the pituitary. Endocr Rev 6: 552-563, 1985.

7. Sano T, Yamada S. Histologic and immunohistochemical study of clinically nonfunctioning pituitary adenomas: special reference to gonadotropin-positive adenomas. Pathol Int 44: 697-703, 1994.

8. Yamada S, Sano T, Stefaneanu L, et al. Endocrine and morphological study of a clinically silent somatotroph adenoma of the human pituitary. J Clin Endocrinol Metab 76: 352-356, 1993.

9. Wass JAH, Reddy R, Karavitaki N. The postoperative monitoring of nonfunctioning pituitary adenomas. Nat Rev Endocrinol 7: 431434, 2011.

10. Horvath E, Kovacs K, Killinger DW, Smyth HS, Platts ME, Singer W. Silent corticotropic adenomas of the human pituitary gland: a histologic, immunocytologic, and ultrastructual study. Am J Pathol 98: 617-638, 1980.

11. Tamiya H, Fukuhara N, Yoshida N, et al. A silent follicle- stimulating hormone-producing pituitary adenoma in a teenage male. Endocr Pathol 22: 212-217, 2011.

12. Losa M, Mortini P, Barzaghi R, Franzin A, Giovanelli M. Endocrine inactive and gonadotroph adenomas: diagnosis and management. J Neurooncol 54: 167-177, 2001.

13. Snyder PJ. Gonadotroph and other clinically nonfunctioning pituitary adenomas. Cancer Treat Res 89: 57-72, 1997.

14. Young WF Jr, Scheithauer BW, Kovacs KT, Horvath E, Davis DH, Randall RV. Gonadotroph adenoma of the pituitary gland: a clinicopathologic analysis of 100 cases. Mayo Clin Proc 71: 649-656, 1996.

15. Dekkers OM, Pereira AM, Romijn JA. Treatment and follow-up of clinically nonfunctioning pituitary macroadenomas. J Clin Endocrinol Metab 93: 3717-3726, 2008.

16. Noh TW, Jeong HJ, Lee MK, Kim TS, Kim SH, Lee EJ. Predicting recurrence of nonfunctioning pituitary adenomas. J Clin Endocrinol Metab 94: 4406-4413, 2009.

17. Breen P, Flickinger JC, Kondziolka D, Martinez AJ. Radiotherapy for nonfunctional pituitary adenoma: analysis of long-term tumor control. J Neurosurg 89: 933-938, 1998.

18. Colao A, Di Somma C, Pivonello R, Faggiano A, Lombardi G, Savastano S. Medical therapy for clinically non-functioning pituitary adenomas. Endocr Relat Cancer 15: 905-915, 2008.

19. $\mathrm{Ph}$. Chanson. Gonadatoroph pituitary adenomas. Annales d'endocrinologie 61: 258-268, 2000 (in French, Abstract in English).

20. Horvath E, Kovacs K. Gonadotroph adenomas of the human pituitary: sex-related fine-structual dichotomy. Am J Pathol 117: 429440, 1984.

(C) 2013 The Japanese Society of Internal Medicine http://www.naika.or.jp/imonline/index.html 